\title{
Comentarios
}

\section{A propósito de la nueva Ley de Zonas Francas}

Las zonas francas están presentes en El Salvador desde principios de la década de 1970, cuando se creó la zona franca de San Bartolo, la cual llegó a albergar un importante grupo de empresas relacionadas con el ensamblaje de diferentes productos, desde textiles hasta productos electrónicos. Las zonas francas of recen grandes ventajas para los inversionistas extranjeros, entre ellas las más significativas se pueden mencionar las siguientes: la exención de impuestos sobre la transferencia de bienes, renta, transferencia de propiedades, así como de los impuestos municipales.

Con el advenimiento de la guerra y la consecuente inestabilidad política, las inversiones en zonas francas decayeron notablemente, pero, a partir de 1992, una vez finalizada la guerra, el gobierno procedió a implementar acciones para atraer mayor inversión extranjera mediante la promulgación de leyes especiales, y la creación de una diversidad de zonas francas $y$ recintos fiscales.

Así, con un importante patrocinio de la Agencia Internacional para el Desarrollo (AID) se procedió a la creación de al menos seis zonas francas, las cuales estarían en capacidad de proporcionar empleo a más de 50,000 personas. La mayoría de empresas que se han instalado en estas zonas se dedican al ensamblaje de prendas de vestir -denominadas "maquilas-, y éstas se encuentran destinadas a satisfacer la demanda en Estados Unidos. Estas reciben su materia prima del exterior y luego la exportan, lo cual implica que sus vínculos con la economía nacional se reducen prácticamente al empleo que generan.
Desde sus inicios, las maquilas han despertado variadas polémicas sobre su funcionamiento, debido al efecto que la transnacionalización de las inversiones textiles tiene sobre el nivel de empleo en los países desde donde emigran las maquilas y, por otra parte, al trato que en ellas se dispensa a las trabajadoras. En variados momentos, incluyendo el presente, los movimientos sindicales estadounidenses han protestado por la política de la AID de promover zonas francas en Centroamérica, pues ello implica fuga de empleos para los trabajadores estadounidenses y reducciones importantes en los salarios que son pagados por las empresas maquileras instaladas en Centroamérica. Por otra parte, los conflictos laborales en las maquilas han llegado a tales niveles que, en diversas ocasiones, provocaron huelgas y despidos masivos de trabajadoras. Con todo, la maquila ha experimentado un franco avance durante la década de 1990, lo cual se refleja en que ha llegado a representar hasta un 44 por ciento de las exportaciones totales en 1997; representa un respetable 9 por ciento de la producción de la industria manufacturera y se estima que ha generado no menos de 50,000 empleos que equivalen a un 13 por ciento de la población ocupada en la industria manufacturera.

Una de las causas más evidentes para el espectacular crecimiento de la maquila ha sido la exención fiscal de la que ha gozado desde siempre, así como de los bajos niveles salariales prevalecientes en el país. Como se mencionó arriba, las actividades de la maquila han estado exentas del pago de todos los impuestos y fundamentan su actividad en la contratación de mano de obra poco calificada, principalmente en la confección de prendas de vestir, a la 
cual se remunera en su mayoría con el equivalente al salario mínimo vigente.

Hasta el mes de septiembre de 1998, las empresas maquileras podían acceder a estas prebendas con sólo comprometerse a no vender sus productos en el mercado nacional, pues ello representaría competencia desleal para empresas que sí pagan sus impuestos y que, consiguientemente, operan con mayores costos.

Esta situación podría cambiar drásticamente, pues en septiembre de 1998 se aprobó una nueva Ley de Zonas Francas, cuyo contenido principal es precisamente la derogación de la prohibición para la venta de la producción maquilera en el mercado local, siempre y cuando se incluya un 50 por ciento de materiales regionales en su elaboración. Hasta ahora, tanto la Asamblea Legislativa como el Presidente de la República han dado su visto bueno a la mencionada ley.

Sin embargo, ello no implica que el proceso haya recibido unánime aprobación. Aunque el Ministerio de Economía afirmó que esta ley había sido consensada con las principales gremiales empresariales, no ha dejado de provocar reacciones adversas en las gremiales representativas de la pequeña empresa, sector agropecuario, exportadores y hasta del Ministerio de Agricultura y Ganadería (MAG). Ciertamente, las posibles implicaciones de la Ley de Zonas Francas justifican un análisis de sus principales cuestionamientos y posibles efectos sobre los sectores productivos, especialmente sobre la rama de textiles y el sector agropecuario.

La polémica en torno a la Ley de Zonas Francas estriba fundamentalmente en que levanta la prohibición a las ventas de las empresas maquileras en el mercado nacional. Como se verá más adelante, éste ha sido el meollo de la discusión y en realidad podría tener implicaciones muy perjudiciales sobre las empresas nacionales, no sólo de la rama textil sino también agropecuaria. Una primera duda surge en torno a la capacidad institucional para hacer cumplir al pie de la letra la ley, en lo que se refiere a garantizar que efectivamente las empresas maquileras utilicen un 50 por ciento de materia prima regional, y que el restante 50 por ciento de materias primas importadas paguen los correspondientes aranceles. Y una segunda en cuanto a cómo se procederá en lo tocante a la exención de impuestos.

En relación con este último aspecto, es importante señalar que, aunque la ley establece que los productos para venta local deberán pagar todos los impuestos, nada garantiza que existirá una verificación efectiva de que esto se cumpla. Adicionalmente, abre la posibilidad de que algunas empresas se instalen en zonas francas, importen productos regionales que tienen menor precio $y$, aun pagando impuestos, se encuentren en posición ventajosa en relación con las empresas nacionales. Esto parece altamente probable en el caso del azúcar.

Otro punto cuestionable de la ley, aunque no tan importante como el anterior, es que no se considera en ella la posibilidad de vender localmente la producción de aparatos electrónicos. Esta rama, a diferencia de los textiles, no está desarrollada en el país y podría implicar importantes beneficios para los consumidores locales e, inclusive, para la mano de obra, sin perjuicio para la industria local.

El efecto más inmediato de la ley podría esperarse en la industria manufacturera. Hay dos ramas que se verían afectadas a corto plazo: textiles y artículos confeccionados de materiales textiles (excepto prendas de vestir) y prendas de vestir. Los efectos en cada uno de los casos serían diferentes. Mientras que la primera rama podría experimentar un incremento de la demanda de sus productos, las prendas de vestir se enfrentarían a mayor competencia debido a la libre comercialización de la producción maquilera.

Es oportuno señalar aquí que, hasta ahora, la materia prima empleada por las empresas maquileras ha sido suplida por importaciones libres de impuestos. Como se mencionó antes, con la ley en mención las maquilas que deseen vender en el mercado local deberán incluir un 50 por ciento de materias primas regionales en sus productos. Esto podría ser una buena noticia para la rama de textiles y artículos confeccionados de materiales textiles, pues implicaría que se convirtieran en proveedores de las empresas maquileras, algo inusitado en la historia de este sector. Sin embargo, eso dependerá de otros factores relacionados con los costos de las maquilas de ropa - los cuales podrían determinar la inviabilidad de la venta local-y los precios de las materias primas del resto de países de la región. En realidad este beneficio es muy dudoso.

Por su parte, las ramas dedicadas propiamente a la confección de prendas de vestir se enfrentarían a un súbito incremento en la oferta de productos similares producidos en las empresas maquileras bajo condiciones más ventajosas, debido a que pagan los 
más bajos salarios posibles $\mathrm{y}$, aun así, obtienen una elevada productividad de sus trabajadoras. En efecto, al revisar los salarios promedio de la industria local se descubre que éstos se encuentran muy por encima del salario mínimo. Por ejemplo, en 1996, los salarios promedio para la rama de la industria en general se encontraban en 1,557.3 - lo cual implica estar ya en condición de pobreza-, mientras que el salario pagado en las maquilas (el mismo salario mínimo legal) era de 1,050 colones.

Por otra parte, tampoco puede negarse que las maquilas imponen una férrea disciplina de trabajo, al grado que a las empleadas no les es permitido levantarse de sus puestos de trabajo, e incluso han llegado al extremo de cronometrar el tiempo empleado para realizar sus necesidades fisiológicas. Debe reconocerse, empero, que pese a cualquier cuestionamiento, este maltrato laboral se traduce en mayor productividad.

El impacto sobre las dos ramas textiles mencionadas podría ser de gran consideración, en especial si se tiene en cuenta de que la maquila ha crecido tanto que prácticamente iguala la suma de las producciones de ambas ramas. Para 1997, la rama de textiles y artículos confeccionados de materiales textiles y la rama de prendas de vestir totalizaron una producción de 682.4 y 232.5 millones de colones a precios constantes de 1990, respectivamente; en conjunto totalizaron los 914.9 millones de colones. Por su parte, la maquila alcanzó, ese mismo año, 813.4 millones de colones a precios constantes de 1990. Las cifras anteriores dejan en claro que la rama más vulnerable es la de las prendas de vestir que apenas representan un 28.5 por ciento de la producción de la maquila.

Como era de esperarse, la ley ha sido objeto de intenso debate durante las últimas semanas, principalmente por sus posibles efectos sobre el sector productivo nacional. Mientras unos atirman que la nueva ley será de beneficio para la economía del país, otros sostienen que únicamente vendrá a provocar el colapso de numerosas empresas de los sectores industrial y agropecuario. Lo cierto es que la nueva Ley de Zonas Francas inarca un importante cambio en relación con sus precedentes, que sólo contemplaban la producción de las empresas ubicadas en zonas francas para fines de exportación.

La intención de promover la venta local de la producción de empresas en zonas francas es un salto cualitativo que no puede aceptarse sin más por dos razones fundamentales: primero la venta local

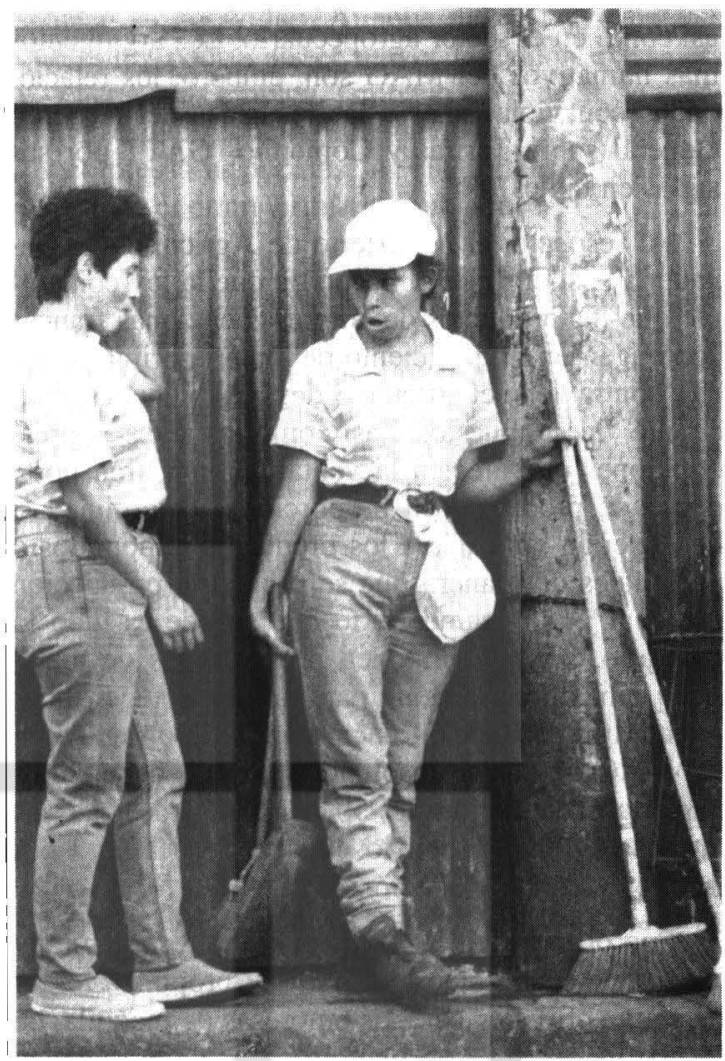

de la producción de maquila implicaría someter a competencia desleal a los productores nacionales $y$, segundo, supondría llevar las concesiones para la inversión extranjera hasta el límite, lo cual sugeriría que la ínica forma de desarrollarse sería mediante la eliminación completa de las harreras para el ingreso de productos y empresas foráneas, aun a costa de las empresas nacionales.

No es de extrañar entonces que la ley haya causado contradicciones de apreciación entre el Ministerio de Economía y el Ministerio de Agricultura y Ganadería en torno a sus posibles efectos sobre las empresas nacionales. Así, el Ministro de Economía, Eduardo Zablah, sostiene que la citada ley "no afecta al productor nacional", pero al mismo tiempo se vio obligado a aceptar más tarde que "no consideró" posibles efectos negativos sobre el sector azucarero y la pequeña y mediana empresa.

Por su parte, el Ministro de Agricultura y Ganadería, Ricardo Quiñónez, se habría pronunciado públicamente por introducir reformas a la ley, pues, tal como está, afirma que provocará efectos negativos sobre la pequeña y mediana empresa industrial 
así como en el sector agropecuario. Los argumentos más llamativos del MAG son, empero, los relacionados con violaciones a las cláusulas del Acuerdo General sobre Tarifas y Comercio (GATT por sus siglas en inglés).

Al respecto, el Ministerio de Agricultura y Ganadería sostiene que el hecho de que la ley contemple que los productos de empresas en zonas francas contengan un 50 por ciento de materia prima regional, contraviene el artículo 3 del GATT que establece que "los impuestos... así como las leyes, y prescripciones que afecten la venta, compra, transporte o uso de productos en proporciones determinadas, no deberían aplicarse a los productos importados o nacionales de manera que se proteja la producción nacional". Curiosamente, lo que sucede es todo lo contrario, pues se imponen proporciones de materias primas precisamente para no desproteger totalmente a la producción nacional. De la observación del MAG, lo que se desprendería es que debe eliminarse la prescripción del 50 por ciento de materias primas regionales, con lo cual se dejaría aún más desprotegida la producción nacional.

Por otra parte, el Ministerio de Agricultura y Ganadería señala que la nueva ley propone otorgar incentivos fiscales para las empresas de maquila, de forma que éstas se encuentren en una clara ventaja en relación con empresas similares ubicadas en el país, pero fuera de las zonas francas. En concreto, los artículos $11,14,17$ y 19 de la citada ley proponen incentivos fiscales que, a juicio del MAG, contravienen otros convenios internacionales que persiguen una eliminación progresiva de los subsidios para el año 2003.

Los argumentos del MAG, aunque probablemente persigan la protección de los productores nacionales, más bien parecen reflejar una postura que busca la eliminación de cualquier tipo de protección para la producción nacional; pero, en todo caso, constituyen crítica abierta para las formulaciones del Ministerio de Economía. Este último, por su parte, se limitó a expresar que los argumentos vertidos por el MAG no son válidos, porque ha interpretado los convenios fuera de contexto y porque las zonas francas son un régimen especial que aún no recibe un tratamiento específico dentro del GATT.

Lo más importante de esta ley no debería ser si violan o no convenios internacionales (sean éstos el GATT o cualquier convenio de integración centroamiericana), sino cómo va a contribuir para el desa- rrollo del país. A criterio de gremiales como la Asociación de Medianos y Pequeños Empresarios, la Comisión Nacional de la Micro y Pequeña Empresa, la Cámara Agropecuaria y la Asociación Azucarera, la citada ley podría provocar cierre de empresas dedicadas a la actividad textil (por ahora, la más difundida dentro de las zonas francas) e, incluso, afectar al sector azucarero pues podría generar el surgimiento de empresas dentro de zonas francas que podrían comprar su azúcar en el exterior $y$, de esa manera, disminuir la demanda de insumos nacionales que afectarían el ingreso de los sectores azucareros y cañeros.

De hecho, durante los últimos días, las especulaciones en este sentido provocaron que no se vendiera un ingenio estatal debido a que la rentabilidad de su operación se vería claramente amenazada con la nueva ley. De acuerdo con versiones periodísticas, que a su vez se apoyan en declaraciones de inversionistas potenciales, si con la nueva ley los consumidores industriales de azúcar pueden importarla (aunque sea en un 50 por ciento), las ventas de los ingenios locales bajarían conjuntamente con su rentabilidad. Probablemente por ello, después de dos días de subasta, no se logró vender ni siquiera la cuarta parte de las acciones del ingenio, pese a que sólo unas semanas antes existían muy buenas expectativas de su venta total a cuatro grupos de inversionistas.

Otras críticas han provenido de la Fundación Salvadoreña de Desarrollo Económico y Social, la cual paradójicamente es otro resultado de los proyectos de la Agencia Internacional para el Desarrollo en El Salvador. Esta sostiene que el artículo 204 de la ley es inconstitucional, ya que persigue otorgar exenciones fiscales sin consultar a los correspondientes Concejos Municipales. Sostiene, además, que la ley crea un posible agujero para que las empresas en zonas francas logren evadir el Impuesto sobre Transferencia de Bienes en sus compras de insumos.

El aspecto más cuestionable de la maquila es que se basa en grandes concesiones de parte de los gobiernos y sólo aportan empleos que, en su mayor parte, sen de baja categoría y mal remunerados. Incluso, expertos en competitividad como Michael Porter han señalado que las posibilidades del desarrollo se reducen si se pretende promover el crecimiento a partir de la maquila, pues "Sólo países que tienen poco que ofrecer atraen inversiones con vacaciones fiscales". 
En la misma línea, la Organización Internacional del Trabajo, un organismo dependiente de la Organización de Naciones Unidas, ha señalado que las zonas francas son una "bendición a medias", pues, aunque son creadoras de puestos de trabajo, a menudo ofrecen bajos salarios y pésimas condiciones laborales. Además, señala que estos sectores carecen de vínculos de consideración con las economías que las rodean.

Para atraer inversionistas extranjeros no es necesario promover leyes que abren cada vez más las puertas para el colapso de la industria y del agro del país, más bien es necesario elevar la calificación de la mano de obra para que pueda desempeñar tareas más complejas, mejor remuneradas y relacionadas con la elaboración de productos con mayor valor agregado que los textiles, y que no compitan con la producción nacional, como los productos electrónicos, por ejemplo.

Lo anterior supone que si el gobierno desea promover el desarrollo a través del crecimiento de la maquila, cuando menos debe aumentar su inversión en capital humano con miras a mejorar los ingresos de los trabajadores de ese sector.

Existe un mosaico de críticas para la nueva ley de zonas francas, de las cuales sólo se señalaron unas pocas en este espacio y que justificadamente señalan su nocividad. Aunque puede argumentarse que la ley podría atraer mayor inversión extranjera y generar más empleo, tampoco debe dejar de mencionarse que reduciría la inversión y el empleo de las empresas nacionales. Al final, pues, los efectos benéficos podrían terminar anulándose.

Este tipo de ley sugiere que el gobierno ya ni siquiera sirve a los intereses de la clase empresarial local, como to hacía en el pasado reciente con la promulgación de leyes que favorecían la actividad cafetalera, industrial, algodonera, etc. Por el contrario, la Ley de Zonas Francas ignora totalmente los efectos sobre la producción nacional en aras de promover la inversión extranjera. Esta política, en realidad, no es nueva y se encuentra en otros instrumentos jurídicos, como la ley de protección de la propiedad intelectual y la ley que regula el transporte, almacenaje y distribución de los derivados del petróleo.

Los cuestionamientos a la ley deben llamar al gobierno a reflexionar sobre la necesidad de desarrollar políticas públicas que centren las expectativas del desarrollo en los sectores productivos nacionales, y no en inversiones especulativas que gustan de "vacaciones fiscales" y no ofrecen mejores perspectivas para la fuerza laboral.

\section{Luis Ernesto Romano Martínez}

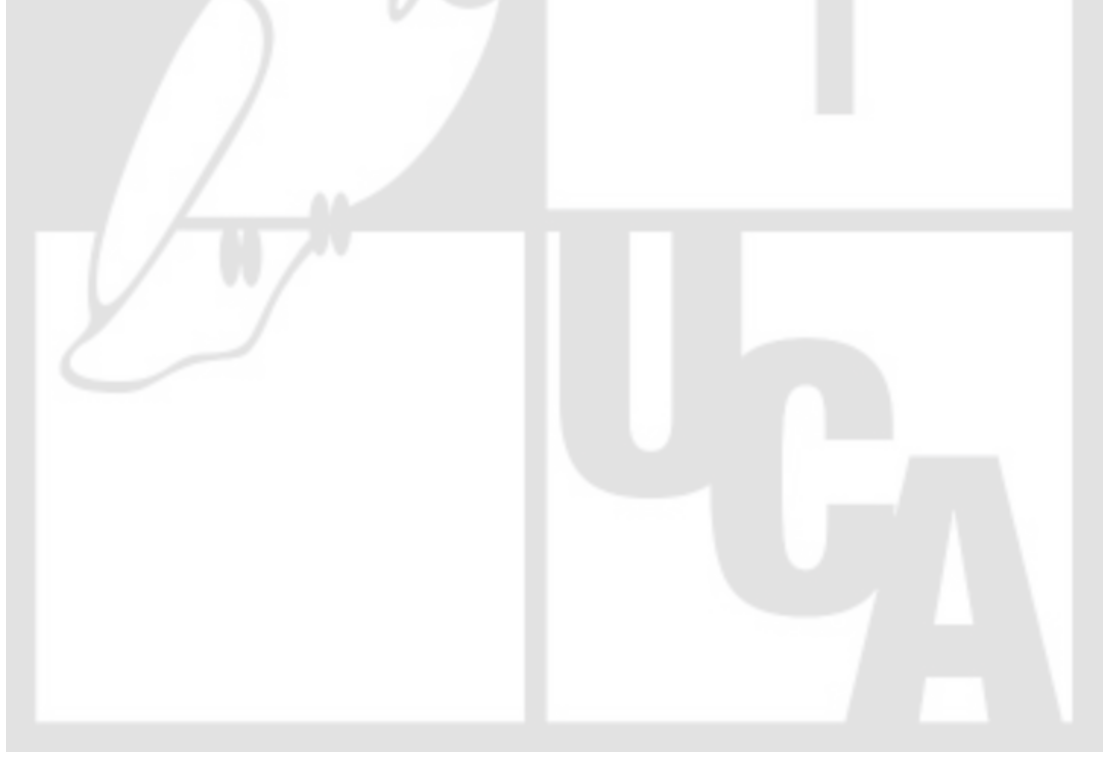

